\title{
Enthalpic vs Entropic Contribution to the Quinone Formal Potential in a Polypyrrole Based Conducting Redox Polymer
}

\author{
Rikard Emanuelsson, ${ }^{\dagger}$ Hao Huang, ${ }^{\dagger}$ Adolf Gogoll, ${ }^{\ddagger}$ Maria Strømme, ${ }^{\dagger}$ and Martin Sjödin ${ }^{\dagger *}$ \\ ${ }^{\dagger}$ Nanotechnology and Functional Materials, Department of Engineering Sciences, The Angström \\ Laboratory, Uppsala University, Box 534, SE-751 21 Uppsala, Sweden \\ $\$$ Department of Chemistry - BMC, Uppsala University, Box 576, SE-751 23 Uppsala, Sweden \\ * E-mail: Martin.Sjodin@angstrom.uu.se
}




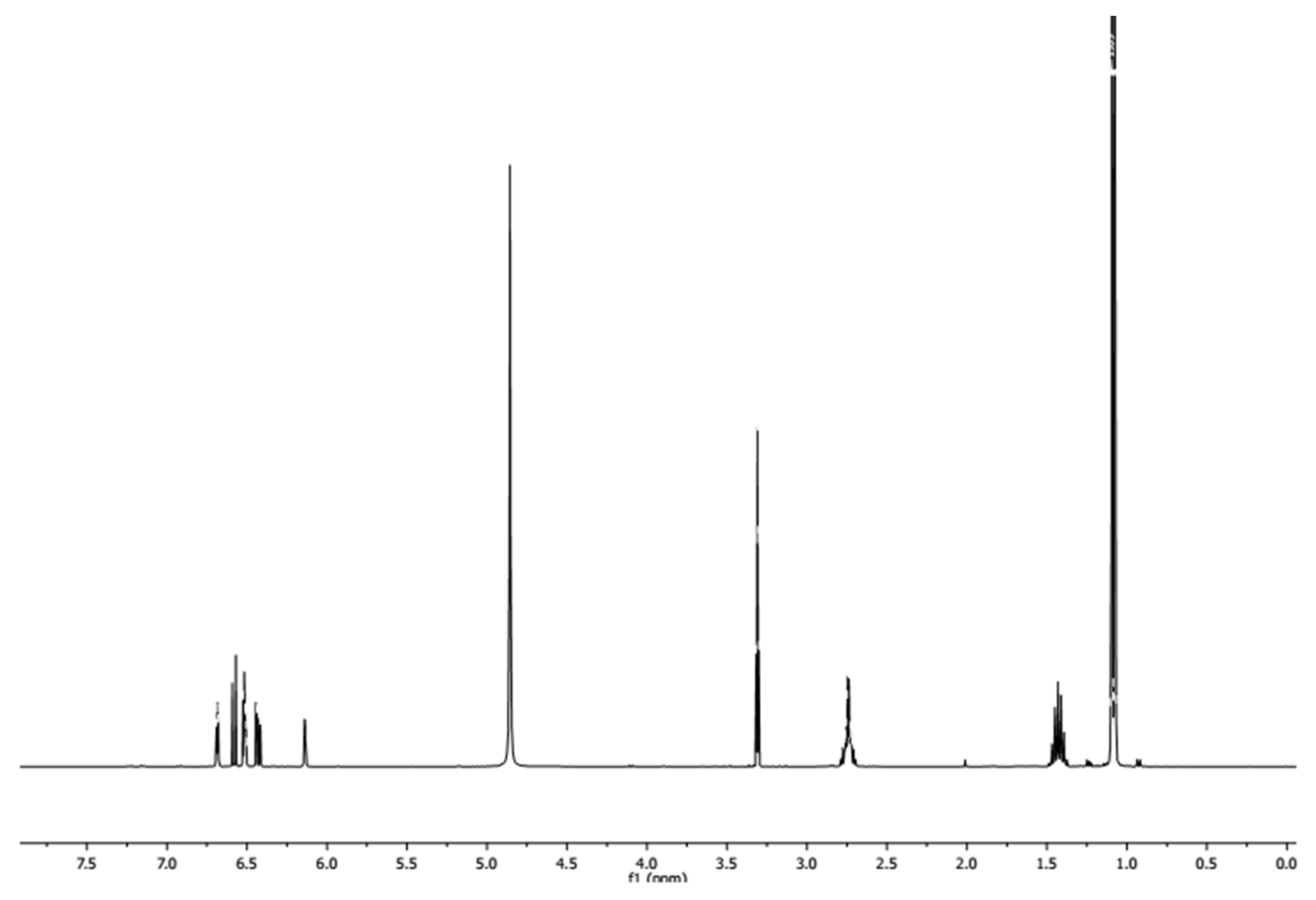

Figure S1. ${ }^{1} \mathrm{H}$ NMR spectrum of 2 in (400 MHz, $\mathrm{CD}_{3} \mathrm{OD}$ solution).
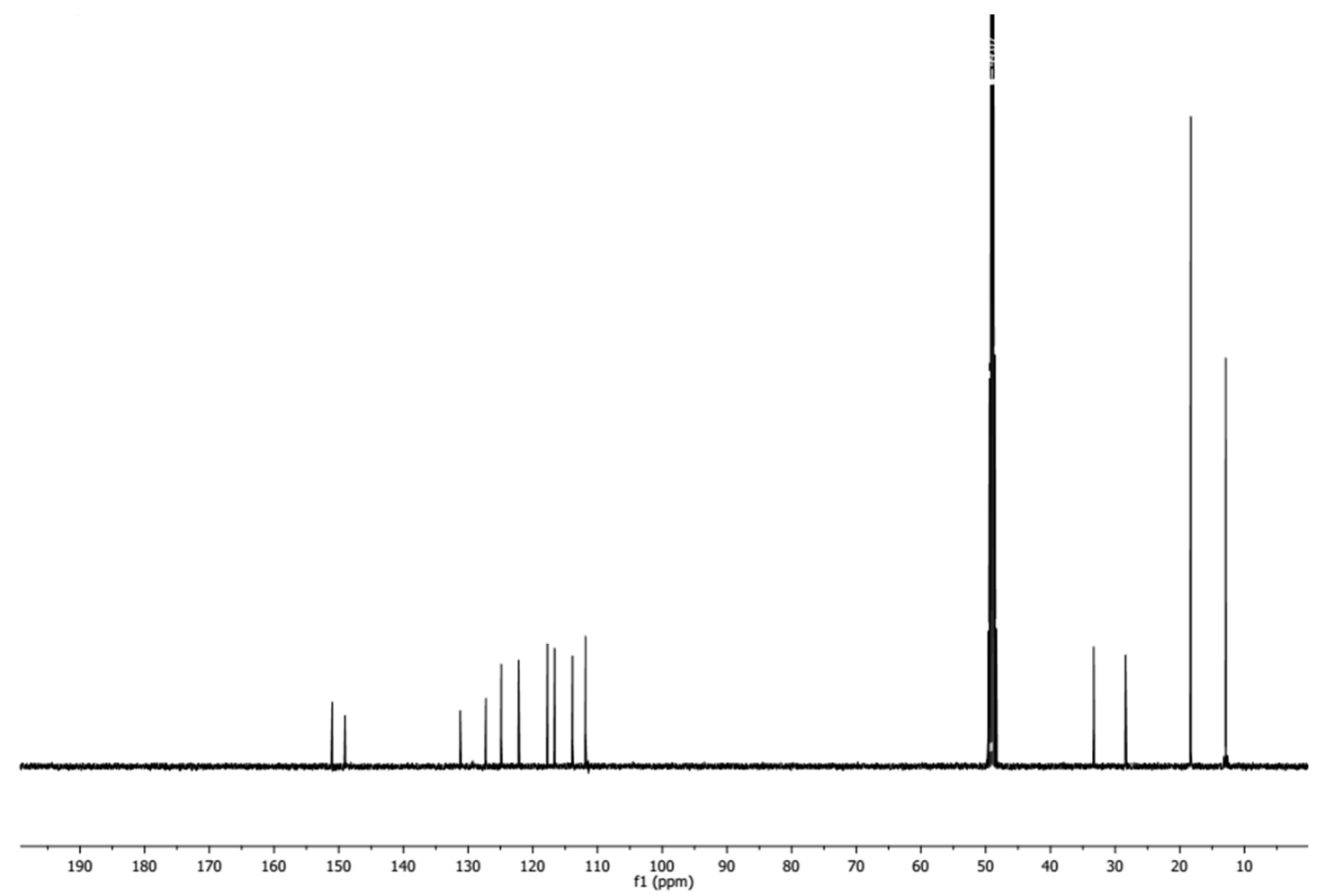

Figure S2. ${ }^{13} \mathrm{C}$ NMR spectrum of $2\left(100 \mathrm{MHz}, \mathrm{CD}_{3} \mathrm{OD}\right.$ solution). 


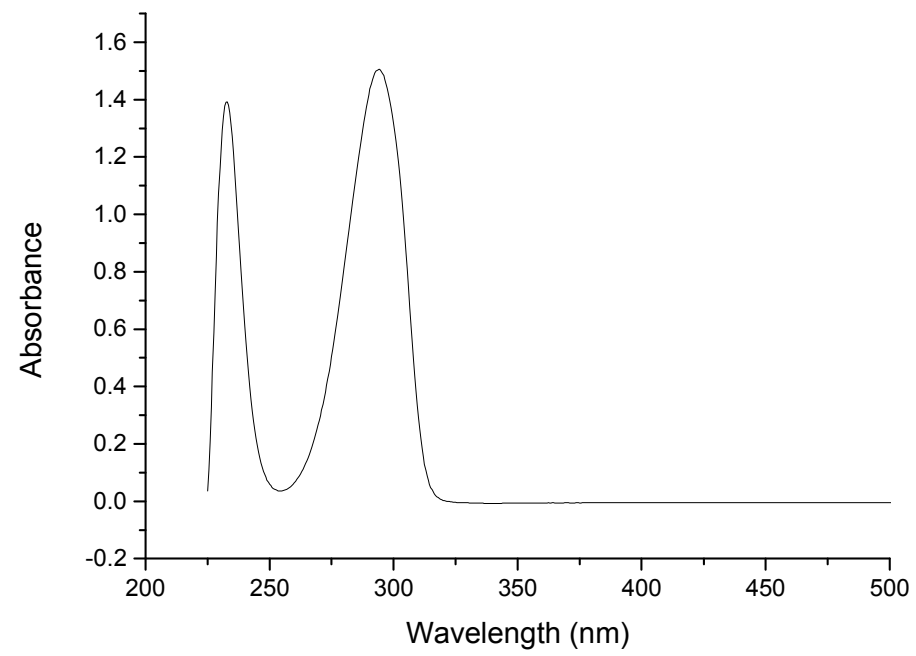

\section{Figure S3}

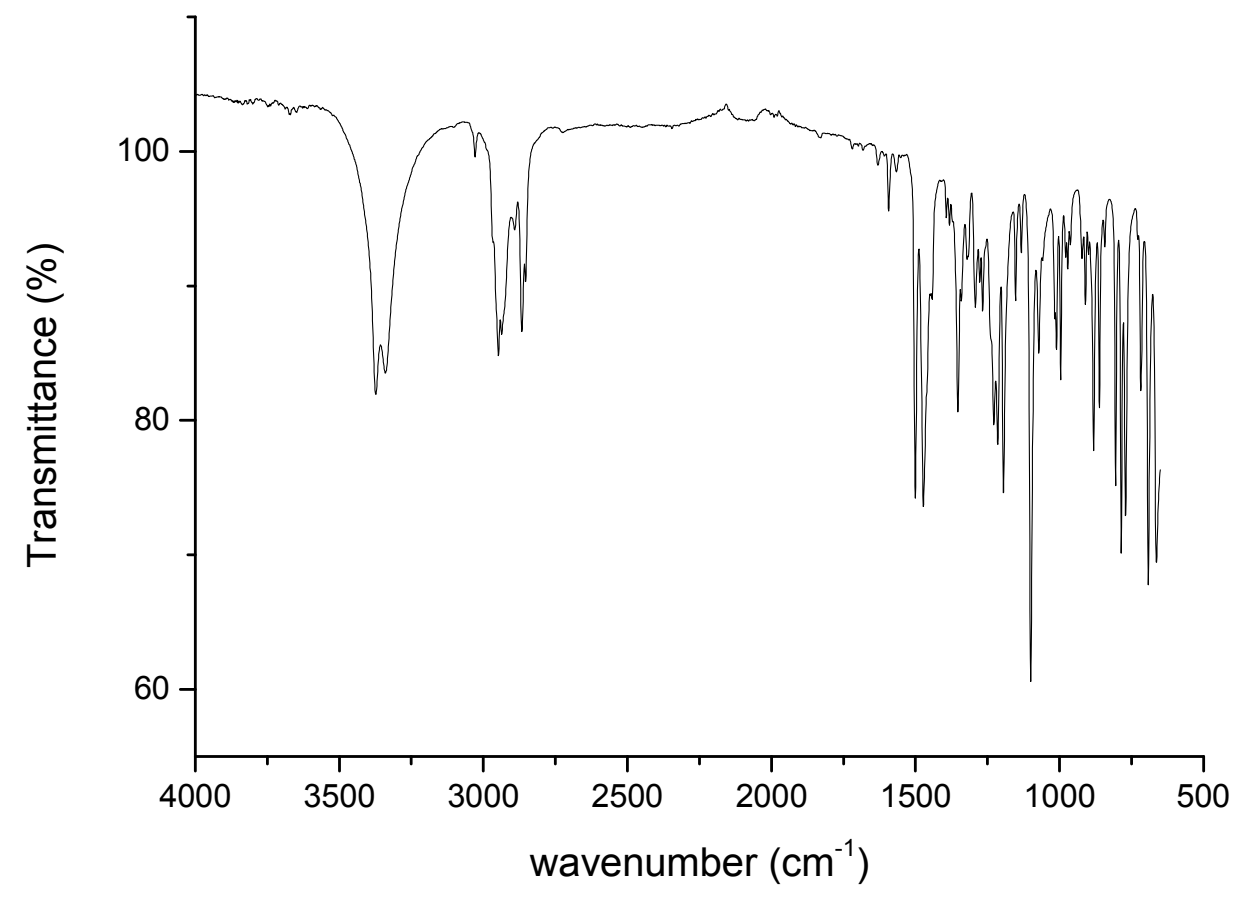

Figure S4. IR spectrum of 2 (neat). 


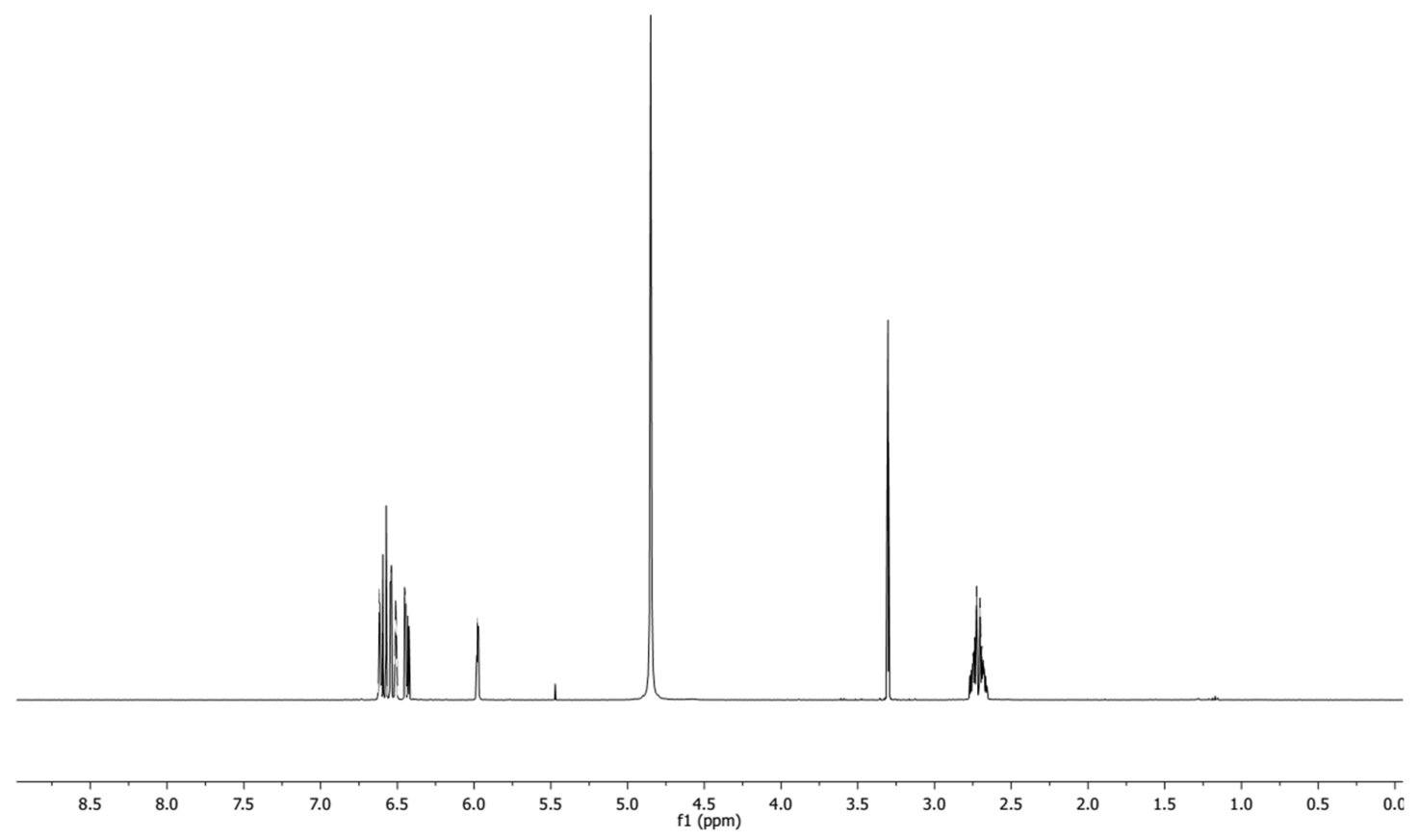

Figure S5. ${ }^{1} \mathrm{H}$ NMR spectrum of 3 (400 $\mathrm{MHz}, \mathrm{CD}_{3} \mathrm{OD}$ solution).

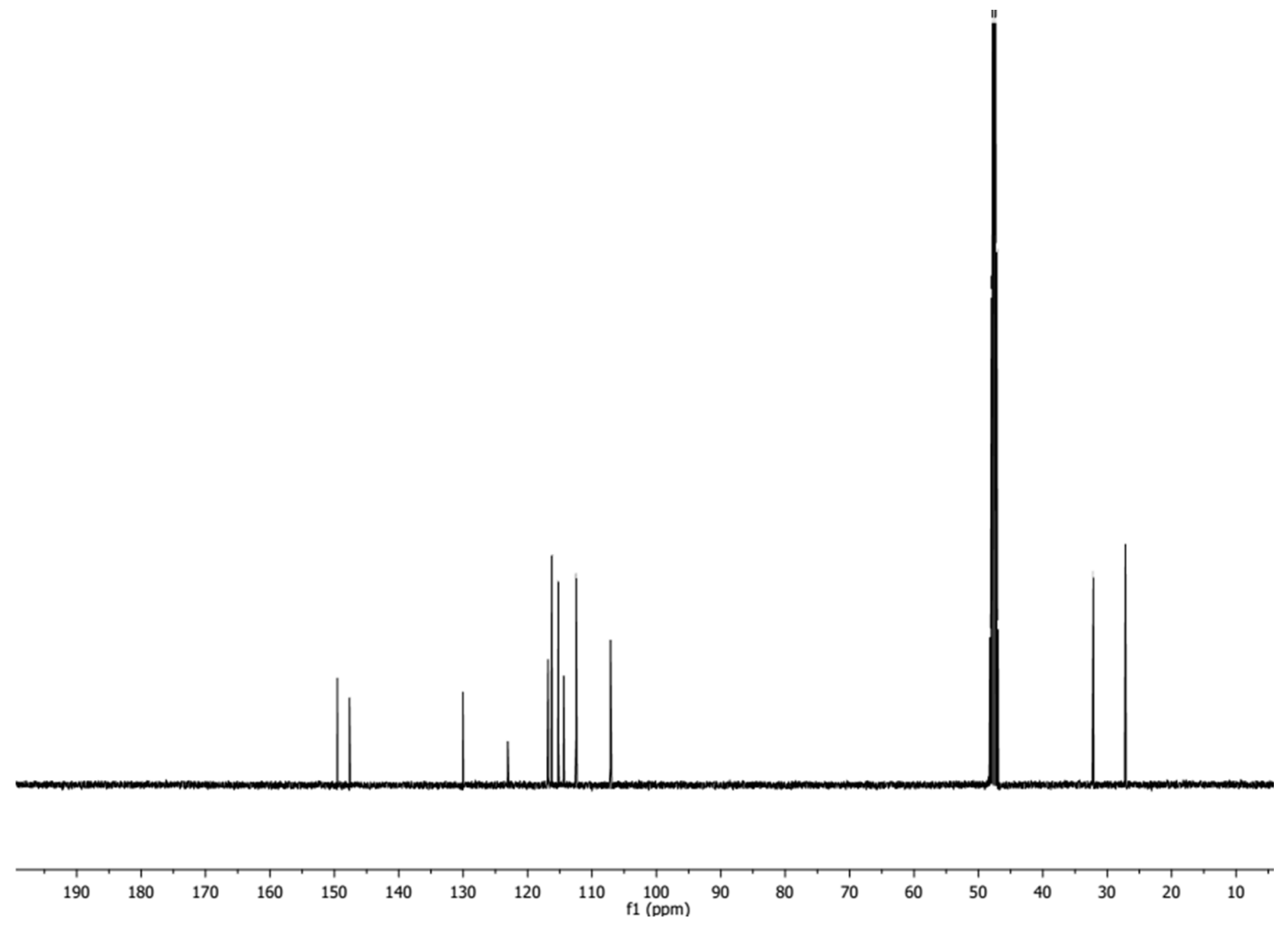

Figure S6. ${ }^{13} \mathrm{C}$ NMR spectrum of $\mathbf{3}$ (100 MHz, $\mathrm{CD}_{3} \mathrm{OD}$ solution). 


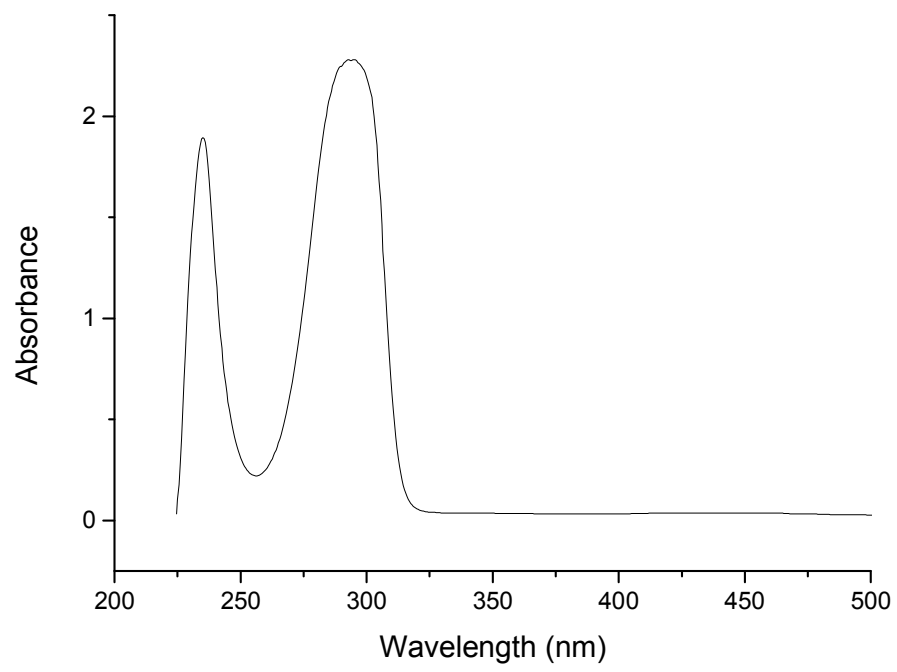

Figure S7. UV spectrum of $\mathbf{3}$ in $\mathrm{MeCN}$ solution.

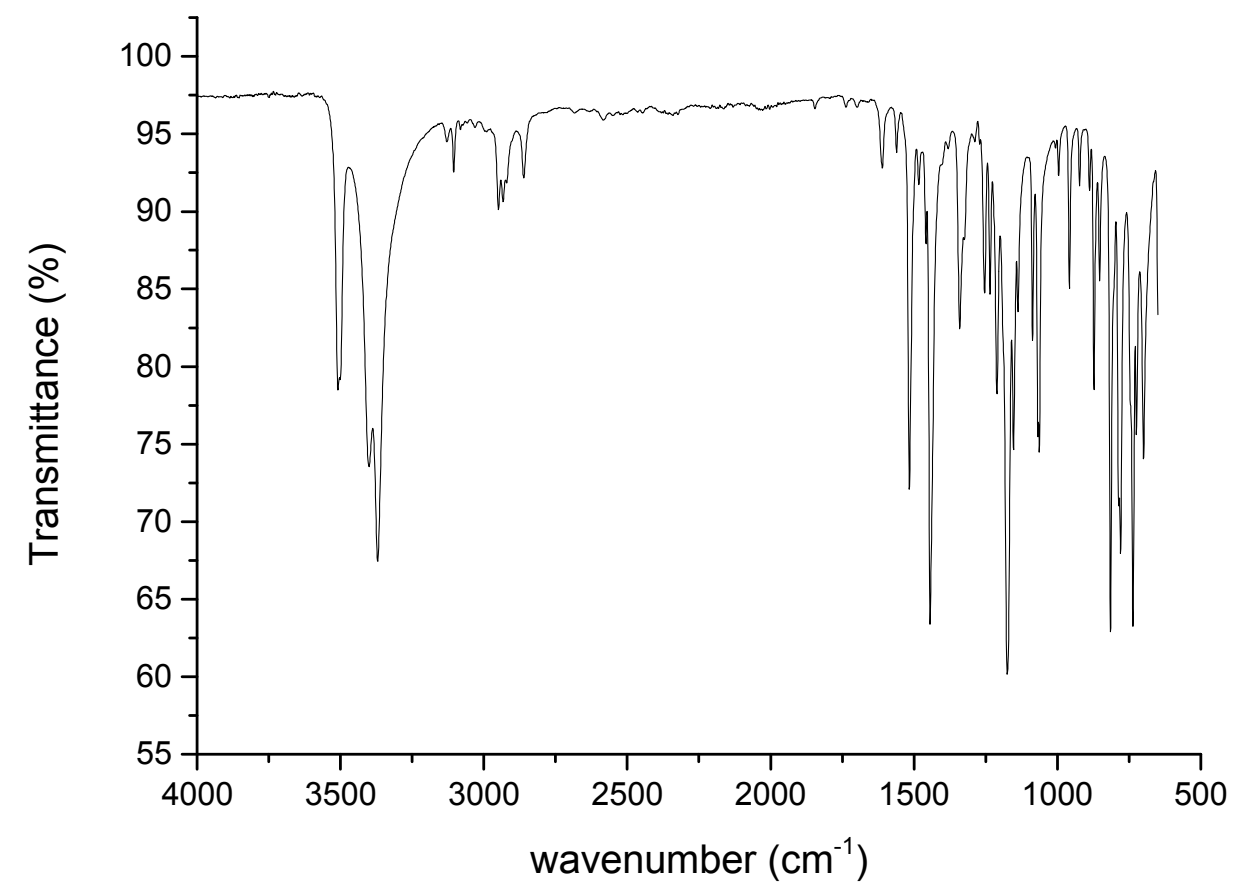

Figure S8. IR spectrum of 3 (neat). 


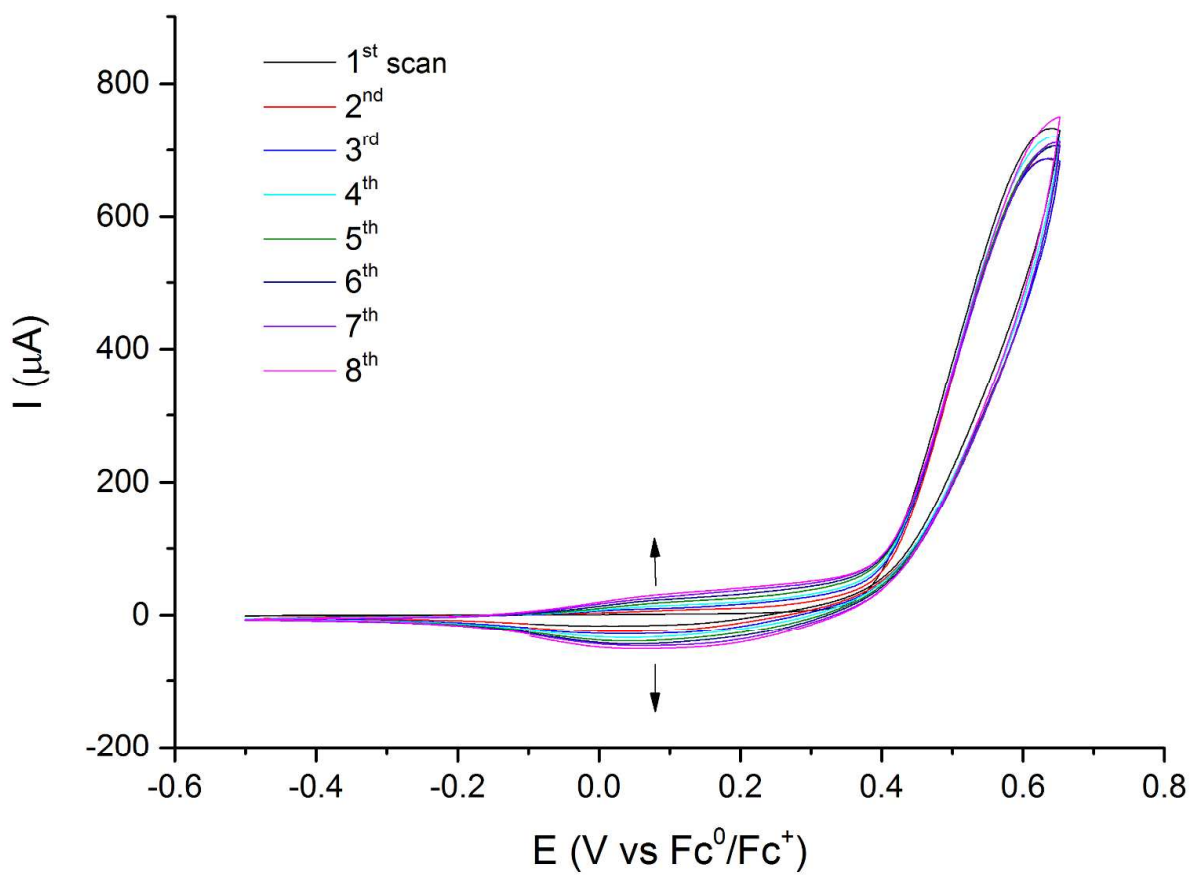

Figure S9. Electropolymerization of $\mathbf{3}$, forming polymer $\mathbf{P 3}$, in $\mathrm{TBAPF}_{6} / \mathrm{MeCN}$ at $100 \mathrm{mV} / \mathrm{s}$.

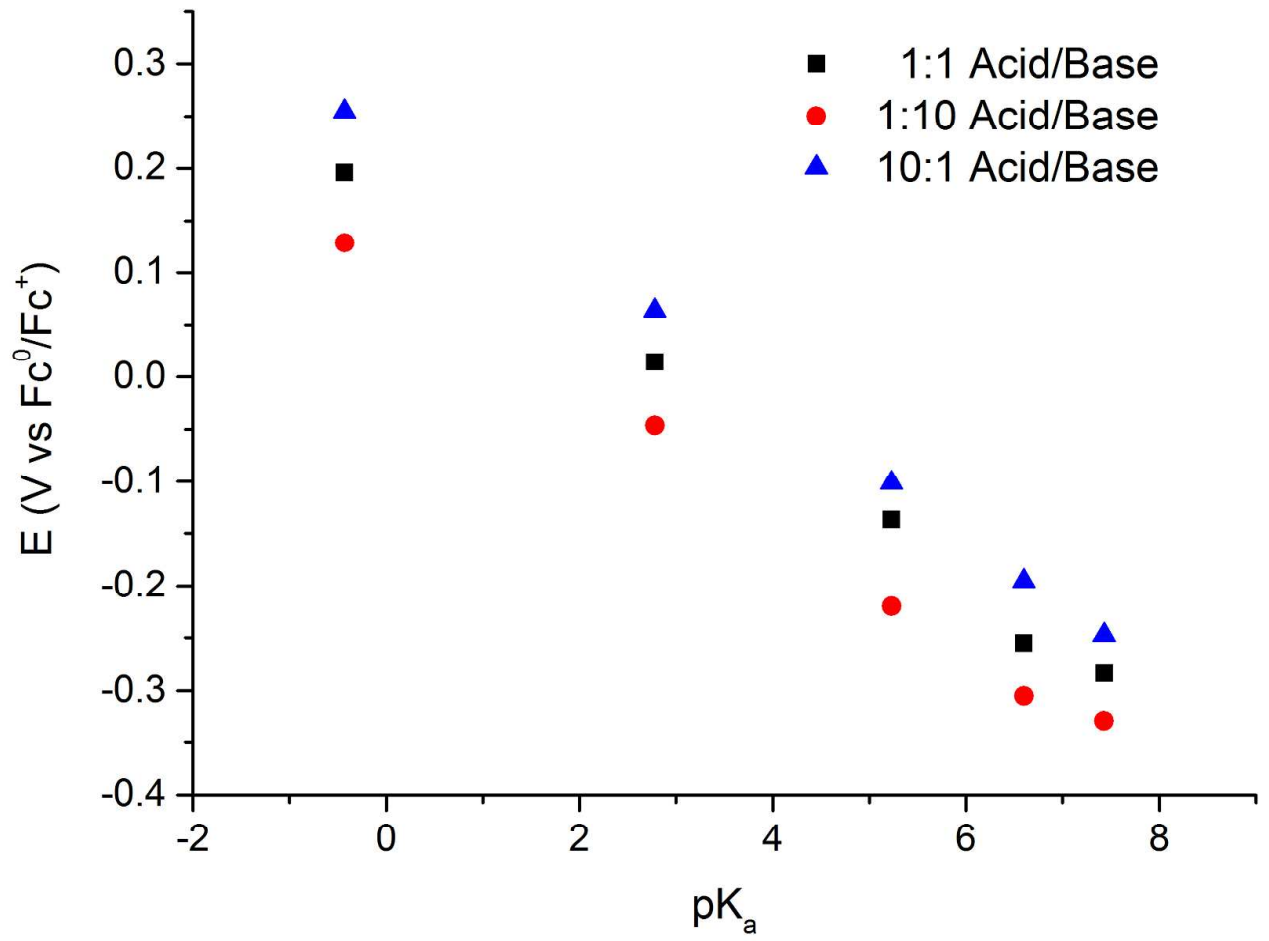

Figure S10. The formal potential $\mathrm{E}^{0 \prime}$ measured at different ratios of organic acid and base. 